IOSR Journal of Pharmacy

e-ISSN: 2250-3013, p-ISSN: 2319-4219, www.iosrphr.org

Vol. 3, Issue 1, Jan.-Feb 2013, PP. 24-28

\title{
Practice Assessment of Adolescent with Type 1 Diabetes in Endocrine Gland Diabetic
}

\author{
Ahmed A. AL-Husaunawy., Najim abass J. Al awwadi., Razzaq J. Al Rubaee., \\ Department of Pharmacology, Faculty of nursing, University of Thi qare Al Nasiriyah - IRAK
}

\begin{abstract}
Diabetes Mellitus is a global health problem, which strikes millions of people worldwide. Objective To assess the Practice of adolescents with "type1 diabetes. Methodology A descriptive study (cross-sectional design) had been done on children with type 1 diabetes, starting from the 26th April 2011 to 26th June 2011. Non -Probability (purposive) sample of (100) children, the ages range between (12-20) years, male and female .Previously diagnosed for at least (3) months with Type 1 diabetes. They visited the Diabetic Center for check -up and get their medicine (insulin). The data are collected through the use of semi-constructed questionnaire, which consists of two parts; (1) Socio demographic data form that consist of 11-items (2) Practice items this part consists of four domain: and(36)domain.

Reliability of the questionnaire is determined through a pilot study and the validity through a panel of (18) experts. The data were described statistically and analyzed through the use of the descriptive and inferential statistical analysis procedures. Results The findings of the present study indicate that the diabetes mellitus affect the Practice domains. The maximal effect presented by the foot care domain, and method of injection domain. There is no significant association of Practice with Demographic, age, Gender, Residency, family history and source of information. But high significant to BMI, Education Level, Reasons effect visit ,Duration\& Information. Recommends the Coordination of the efforts between the Ministry of Health and the staff of diabetes clinics in collaborative team -work to edit a national guide- booklet; one for health providers and another for people with diabetes mellitus, producing an attractive way for readers according to their age groups, and generalized all over the clinics concerning with diabetes in this country and the Expansion of the building and opening new departments that include( eye, neurology, dental, and Nutrition)
\end{abstract}

Keywords: Diabetes Mellitus, Adolescents, Descriptive study, Cross-sectional design, Data collection.

\section{INTRODUCTION}

Diabetes mellitus is not one disease. It is defined as chronic hyperglycemia that may be caused by one or more of numerous underlying processes. Some of these cause diabetes directly by interfering with beta cell function or through significant defects in insulin action. There are two major classifications of diabetes, namely, Type I and Type II. (ADA.(2)

\section{Methodology}

Study Design- A descriptive study (cross-sectional design) had been done on children with type 1 diabetes, starting from the 26 April 2011 to the end of 26 June 2011. To assess the Practice of children with type 1 diabetes, relation to the definition of disease, Care to Signe \&Symptoms, Item of dental care, method of needle injection and Looking to feet.

\section{Data Collection}

Method of data collection had been done by the researcher through the direct interview with children using structured approach of data collection (questionnaire) which is the formal document used to collect and record information. The questionnaire constructed after reviewing in depth related literature and concern about the importance of Knowledge and practices with type 1 diabetes

\section{Data Analysis:}

The data analyzed through the application of statistical procedures and using the package of SPSS version (10). 
Results and Findings

Table (1): Distribution of the demographical characteristics and some related variables to the studied sample

\begin{tabular}{|c|c|c|c|c|}
\hline $\begin{array}{l}\begin{array}{l}\text { Demographics } \\
\text { Variable }\end{array} \\
\end{array}$ & \multicolumn{2}{|l|}{ Groups } & $\begin{array}{l}\text { NO. } \\
\text { Frequenc } \\
\text { y }\end{array}$ & $\begin{array}{l}\text { Percent } \\
\%\end{array}$ \\
\hline \multirow{3}{*}{ Age Groups } & \multicolumn{2}{|l|}{$12-14$} & 57 & 57 \\
\hline & \multicolumn{2}{|l|}{$15-17$} & 27 & 27 \\
\hline & \multicolumn{2}{|l|}{$18-20$} & 16 & 16 \\
\hline \multirow{2}{*}{ Gender } & \multicolumn{2}{|l|}{ Male } & 54 & 54 \\
\hline & \multicolumn{2}{|l|}{ Female } & 46 & 46 \\
\hline \multirow{2}{*}{ Environment ( Residency ) } & \multicolumn{2}{|l|}{ urban } & 39 & 39 \\
\hline & \multicolumn{2}{|l|}{ rural } & 61 & 61 \\
\hline \multirow{3}{*}{ Body Mass Index - BMI } & \multicolumn{2}{|c|}{ under weight } & 51 & 51 \\
\hline & \multicolumn{2}{|c|}{ normal weight } & 39 & 39 \\
\hline & \multicolumn{2}{|c|}{ over weight } & 10 & 10 \\
\hline \multirow{4}{*}{ Educational Level } & \multicolumn{2}{|l|}{ Illiterate } & 9 & 9 \\
\hline & \multicolumn{2}{|c|}{ Read and Writing } & 28 & 28 \\
\hline & \multicolumn{2}{|c|}{ Primary school } & 41 & 41 \\
\hline & \multicolumn{2}{|c|}{ Intermediate school } & 22 & 22 \\
\hline \multirow{5}{*}{ visit of diabetes clinic } & \multicolumn{2}{|c|}{ Regular visit } & 64 & 64 \\
\hline & \multirow{4}{*}{$\begin{array}{l}\text { Irregula } \\
\mathbf{r} \\
\text { visit }\end{array}$} & Low income & 4 & 4 \\
\hline & & $\begin{array}{l}\text { Fare away to } \\
\text { diabetic }\end{array}$ & 11 & 11 \\
\hline & & $\begin{array}{l}\text { Family } \\
\text { causes }\end{array}$ & 10 & 10 \\
\hline & & Other & 11 & 11 \\
\hline \multirow{9}{*}{ Family history } & Negative & & 58 & 58 \\
\hline & & Father & 5 & 5 \\
\hline & & Mother & 2 & 2 \\
\hline & & Grandfather & 9 & 9 \\
\hline & & Grandmother & 3 & 3 \\
\hline & $\begin{array}{l}\text { Positiv } \\
\text { e }\end{array}$ & $\begin{array}{l}\text { Uncle to } \\
\text { father }\end{array}$ & 7 & 7 \\
\hline & & $\begin{array}{ll}\text { Uncle1 } \\
\text { mother }\end{array}$ & 8 & 8 \\
\hline & & Brother & 3 & 3 \\
\hline & & Sister & 5 & 5 \\
\hline & Yes & & 81 & 81 \\
\hline Information level & No & & 19 & 19 \\
\hline & Health e & lucation unit & 55 & 67.9 \\
\hline information sources & Doctor & & 18 & 22.2 \\
\hline & Self educ & ation & 8 & 9.9 \\
\hline & $<1$ yrs. & & 12 & 12 \\
\hline Duration Illness & $1-5 \mathrm{yr}$ & & 70 & 70 \\
\hline & $>5 \mathrm{yrs}$. & & 18 & 18 \\
\hline
\end{tabular}


Table (2): Descriptive Statistics for the Practice items of Juveniles who effected by diabetes ( type 1)

\begin{tabular}{|c|c|c|c|c|c|c|}
\hline \multicolumn{2}{|c|}{$\begin{array}{l}\text { Practices of Juveniles who affected by diabetes } \\
\text { ( Type 1) }\end{array}$} & \multirow[t]{2}{*}{ No. } & \multirow[t]{2}{*}{ M.S. } & \multirow[t]{2}{*}{ S.D. } & \multirow[t]{2}{*}{ R.S. } & \multirow[t]{2}{*}{ Ass. } \\
\hline 3 & Reaction of adolescent care of singe and Symptoms & & & & & \\
\hline $3-1-1$ & body energy & 100 & 1.18 & 0.52 & 39.33 & $\mathbf{F}$ \\
\hline $3-1-2$ & prevent hypoglycaemia & 100 & 2.12 & 0.86 & 70.67 & $\mathbf{P}$ \\
\hline $3-1-3$ & Fruits and leafy vegetables & 100 & 1.72 & 0.82 & $\mathbf{5 7 . 3 3}$ & $\mathbf{F}$ \\
\hline $3-1-4$ & Amount of fluid & 100 & 1.21 & 0.56 & $4 \mathbf{4 0 . 3 3}$ & $\mathbf{F}$ \\
\hline $3-2$ & Dental Care & & & & & \\
\hline $3-2-1$ & Oral hygiene & 100 & 1.45 & 0.69 & 48.33 & $\mathbf{F}$ \\
\hline $3-2-2$ & Teeth and gum infected & 100 & 1.13 & 0.37 & 37.67 & $\mathbf{F}$ \\
\hline $3-2-3$ & Examine my teeth & 100 & 1.33 & 3.01 & 44.33 & $\mathbf{F}$ \\
\hline $3-3$ & Injection method & & & & & \\
\hline $3-3-1$ & Store & 100 & 2.37 & 0.88 & 79.00 & $\mathbf{P}$ \\
\hline $3-3-2$ & Dose & 100 & 2.30 & 0.92 & 76.67 & $\mathbf{P}$ \\
\hline $3-3-3$ & check up vial & 100 & 1.10 & 0.36 & 36.67 & $\mathbf{F}$ \\
\hline $3-3-4$ & Hand clean & 100 & 1.17 & 0.49 & 39.00 & $\mathbf{F}$ \\
\hline $3-3-5$ & Shake the vial & 100 & 1.89 & 0.93 & 63.00 & $\mathbf{F}$ \\
\hline $3-3-6$ & Sterilization & 100 & 1.54 & 0.82 & 51.33 & $\mathbf{F}$ \\
\hline $3-3-7$ & Avoid the inflammation & 100 & 1.20 & 0.57 & 40.00 & $\mathbf{F}$ \\
\hline $3-3-8$ & Injection places sterilization & 100 & 1.38 & 0.74 & 46.00 & $\mathbf{F}$ \\
\hline $3-3-9$ & Air bubbles & 100 & 2.39 & 0.87 & 79.67 & $\mathbf{P}$ \\
\hline $3-3-10$ & Amount of insulin & 100 & 2.38 & 0.90 & 79.33 & $\mathbf{P}$ \\
\hline $3-3-11$ & Grasp & 100 & 1.19 & 0.53 & 39.67 & $\mathbf{F}$ \\
\hline $3-3-12$ & Angle & 100 & 1.38 & 0.75 & 46.00 & $\mathbf{F}$ \\
\hline $3-3-13$ & Syringe units & 100 & 2.20 & 0.94 & 73.33 & $\mathbf{P}$ \\
\hline
\end{tabular}

Continue Table (2)

\begin{tabular}{|l|l|l|l|l|l|l|}
\hline $\begin{array}{l}\text { Practices of Juveniles who affected by diabetes } \\
\text { ( Type })\end{array}$ & No. & M.S. & S.D. & R.S. & Ass. \\
\hline $3-3-14$ & Pressure on skin after injection & $\mathbf{1 0 0}$ & $\mathbf{1 . 1 2}$ & $\mathbf{0 . 4 1}$ & $\mathbf{3 7 . 3 3}$ & F \\
\hline $3-3-15$ & Measurement glucose & $\mathbf{1 0 0}$ & $\mathbf{1 . 3 9}$ & $\mathbf{0 . 6 8}$ & $\mathbf{4 6 . 3 3}$ & F \\
\hline $3-3-16$ & Change the injection & $\mathbf{1 0 0}$ & $\mathbf{1 . 2 4}$ & $\mathbf{0 . 5 9}$ & $\mathbf{4 1 . 3 3}$ & F \\
\hline $3-4$ & Feet care & & & & & \\
\hline $3-4-1$ & Skin cleanness & $\mathbf{1 0 0}$ & $\mathbf{1 . 1 6}$ & $\mathbf{0 . 4 9}$ & $\mathbf{3 8 . 6 7}$ & F \\
\hline $3-4-2$ & Examine my feet & $\mathbf{1 0 0}$ & $\mathbf{1 . 2 4}$ & $\mathbf{0 . 6 1}$ & $\mathbf{4 1 . 3 3}$ & F \\
\hline $3-4-3$ & Family & $\mathbf{1 0 0}$ & $\mathbf{1 . 7 2}$ & $\mathbf{0 . 8 9}$ & $\mathbf{5 7 . 3 3}$ & F \\
\hline $3-4-4$ & Feet hygiene & $\mathbf{1 0 0}$ & $\mathbf{1 . 2 0}$ & $\mathbf{0 . 5 9}$ & $\mathbf{4 0 . 0 0}$ & F \\
\hline $3-4-5$ & Change socks & $\mathbf{1 0 0}$ & $\mathbf{1 . 1 5}$ & $\mathbf{0 . 4 6}$ & $\mathbf{3 8 . 3 3}$ & F \\
\hline $3-4-6$ & Shoes & $\mathbf{1 0 0}$ & $\mathbf{1 . 3 1}$ & $\mathbf{0 . 6 1}$ & $\mathbf{4 3 . 6 7}$ & F \\
\hline $3-4-7$ & Warm water & $\mathbf{1 0 0}$ & $\mathbf{1 . 5 5}$ & $\mathbf{0 . 8 3}$ & $\mathbf{5 1 . 6 7}$ & F \\
\hline $3-4-8$ & Nails & $\mathbf{1 0 0}$ & $\mathbf{1 . 1 2}$ & $\mathbf{0 . 3 8}$ & $\mathbf{3 7 . 3 3}$ & F \\
\hline $3-4-9$ & Rub & $\mathbf{1 0 0}$ & $\mathbf{1 . 2 1}$ & $\mathbf{0 . 5 6}$ & $\mathbf{4 0 . 3 3}$ & F \\
\hline $3-4-10$ & skin ointment & $\mathbf{1 0 0}$ & $\mathbf{1 . 2 7}$ & $\mathbf{0 . 6 5}$ & $\mathbf{4 2 . 3 3}$ & F \\
\hline $3-4-11$ & walking & $\mathbf{1 0 0}$ & $\mathbf{1 . 1 7}$ & $\mathbf{0 . 5 1}$ & $\mathbf{3 9 . 0 0}$ & F \\
\hline $3-4-12$ & Hot exposing & $\mathbf{1 0 0}$ & $\mathbf{1 . 2 8}$ & $\mathbf{0 . 5 9}$ & $\mathbf{4 2 . 6 7}$ & F \\
\hline $3-4-13$ & washing hot or cold water & $\mathbf{1 0 0}$ & $\mathbf{1 . 2 0}$ & $\mathbf{0 . 4 3}$ & $\mathbf{4 0 . 0 0}$ & F \\
\hline
\end{tabular}




\section{Discussion of the Results}

Table (2): Distribution of the Demographical Characteristics and some Related variables to the Studded Sample. Table (2) shows that the adolescent distributed to 3 majorities according to their age and the vast majority (57\%) represent the age group (12-14 yer). And this group represent the early adolescent in which the peak of diabetic accrued and this is may be due to hormonal changes and infections disease. This result agree with Jeannette (4),and this result also comes along with Zeidan, (10). Regarding gender we see little variation in both gender and is quite similar to other studies AL-Azzawi(1) The result indicated that the age of onset of diabetes in this study was more predominant in the age of (<_10) years. while in residency we see most of cases come from rural areas $(61 \%)$ and this may be related to the environment, exposure to infection, diet, life style......etc. Concerning ( BMI), we found most of the case were underweight (51\%) and this explained by late presentation, poor control and appearance of complication of high blood sugar. This result agrees with (3). Relative education level we can see most of the cases $>(41 \%)$ were primary school children and this expand by most of diabetic child leave school either due to over protection or complication of disease itself or teasing by other met class ,this result conflicting (4) in their study which is entitled with (Diabetes knowledge, beliefs and practices among people with diabetes). Regarding to the visit of diabetes clinic, the majority of the sample (64\%) show this result have regular visit to clinic ,that related to adolescent have highly knowledge because relative family knowledge, and irregular visit include (5\%)low income (11\%)faraway from clinic (11\%)include other eg: busy parent, child neglect and miss appointment, Regarding to family history . we found more than $50 \%$ of case have negative family history of DM, while positive family history of DM, for all family pedigree was $<10 \%$ of studied Regarding to the information level, we see the majority of the studied sample are $(81 \%)$ when asked about the disease and complication were positive(they know information about diabetes. Regarding the information source: in this group of studied sample we see most of the adolescent got their information about the disease from health education unit and this is explained by that every patient consult diabetic clinic should consult health education unit according to physician order. Regarding duration of illness we see two third of studied sample have a disease from 1-5 years and this is may be due to that this adolescent and their family believe that the disease is established and no spontaneous cure unless they seek medical advice.

Table (2): Mean of Score, Standard Deviation, and Relative Sufficiency of the Diabetes Mellitus Diseases adolescent Practices Concerning Food Care, Dental Care, Injection Method ,Foot Care of Diabetes. This table Showed reaction of adolescent with DM to the signs and symptoms of DM. all questions failed to pass except hypoglycemia, and its prevention . because most of the adolescent have well understanding for signs and symptoms of hypoglycemia and they know how to prevent such event. These results are supported by Jennifer et al. (5) While questions related to dental care all are passed. because teeth are exposure structure and its part of general appearance of human being also consider one of cosmetic structure of the body. This result is supported by Orlando,(6) Regarding to questions related to injection methods of insulin ,most of them failed except, storage of medicine, dose, air bubble, amount of injected units of insulin and syringe unit . and this explained by the adolescent mainly oriented toward insulin therapy (doses, storage and amount of insulin syringe unit) and (adolescent) consider these are not important as insulin this result support with(7) Regarding foot care, all questions are failed and this in may be due to that foot is un exposed area to index case and community and little information about diabetic foot. These results disagree with the recommendation of the (9)

\section{Conclusions, Recommendations}

According to the present study findings, we make the following conclusions:

1- Incidence of DM. Type 1 is higher in rural area than urban one .

2- Males to females ration with about 1:1

3- Most cases of underweight were primary school children.

4- children who regularly visit diabetes clinic had better practices do not differ significantly

5- Children who had first or second- degree relatives with type1 diabetes had almost the same level of practices as those who did 't have

6- There is no significant association of practices with demographic, age, gender, residency, family history, source of information, But significantly associated with BMI, education level, reasons effect visit to diabetic clinic, duration of illness and Information level .

7- The study recommends the Coordination of the efforts between the Ministry of Health and the staff of diabetes clinics in collaborative team work to edit a national guide booklet; one for health providers and another for people with diabetes mellitus, producing an attractive way for readers according to their age groups, and generalized all over the clinics concerning with diabetes in this 
country and the Expansion of the building and opening new departments that include( eye, neurology, dental, and Nutrition)

\section{REFERENCE}

[1]. AL-Azzawi abdul-Kadir Knowledge and Practices of young Adolescents with type" 1 Diabetes"Related to Self-Administration of Insulin. (2002)Pp23,24.

[2]. American Diabetes Association. Standards of Medical Care in Diabetes-2008. Diabetes Care. 2008;31:S12-S54.

[3]. Evertsen ,Jennifer .,Increasing Incidence of Pediatric Type 1 Diabetes Mellitus in Southeastern Wisconsin: Relationship with Body Weight at Diagnosis, September 2009, Volume 4 , Issue 9 ,p6873

[4]. Jeannette, M.,Rossello, Maria I., Jimenenz,Chafey.,Cognitive-Behavioral Group Therapy for Depression in Adolescents with Diabetes: APilot Study, Revista Interamericana dePsicologia/Interamerican Journal of Psychology - University of Puerto Rico, Rio Piedras, Puerto Rico ,2006, Vol. 40, Num. 2 pp. 219-226

[5]. Jennifer Buccino BASc RD CDE, Katherine Murray BSc, Sarah Farmer BSc . Systematic Review of the Dietary Management of Children With Type 1 Diabetes, dietary management of children with type 1 diabetes, University of Toronto, ortavio, Canada(2003) p219

[6]. Orlando, Valerie A. Oral Health Knowledge and Behaviors among Adolescents with Type 1 Diabetes International Journal of Dentistry Volume8 (2010) Pp10,1155.

[7]. Palaian Subish,2006), Attitude, and Practice Outcomes: Evaluating the Impact of Counseling in Hospitalized Diabetic Patients in India. Knowledge, Vol. 31 No. 7 , July 2006 ,p 389.

[8]. Rafique G, White T,AzamS.I ., , beliefs and practices among people with diabetes attending a university hospital in Karachi, Pakistan. WHO Diabetes knowledge, Volume 12 No 5 September 2006.

[9]. RNAO, Registered Nurses' Association of Ontario (2005). Assessment and Management of Foot Ulcers for People with Diabetes. Toronto, Canada: Registered Nurses', p25.

[10]. Zeidan Muna , they studied the Growth Status of A Sample of Children with( Type1 )Diabetes Mellitus In Baghdad Governorate, College of Health and Medical Technology, 2010, p 39 